\title{
A content analysis for Children's Chinese Reader and its implications
}

Qiao-Yu Cai ( $\nabla$ iku1212@hotmail.com )

National Taichung University of Education https://orcid.org/0000-0002-7282-0660

Feng-Mei Chao

National Taichung University of Education

\section{Method Article}

Keywords: content analysis, teaching Chinese language to children of other languages (COL), COL textbook, textbook evaluation

Posted Date: March 7th, 2022

DOI: https://doi.org/10.21203/rs.3.rs-1410372/v1

License: (c) (1) This work is licensed under a Creative Commons Attribution 4.0 International License. Read Full License 
A content analysis for Children's Chinese Reader and its implications

$$
\text { Qiao-Yu Cai }
$$

Department of Language and Literacy

Education, National Taichung

University of Education
Feng-Mei Chao

\author{
Chinese Language Center
}

National Taichung University of

Education

\begin{abstract}
Chinese learning materials for children has yet to be explored. This study revises the assessment form in Chinese Learning Materials Design Prerequisites, developed by Wang in 2008, to evaluate Chinese learning materials for Children, with a focus on a book series entitled Children's Chinese Reader published by the Overseas Community Affairs Council in Taipei, Taiwan. The purpose of this study is two-fold. The first attempt is to find out the potential merits and the drawbacks that need addressing urgently. The second attempt is to see the potentiality of using the same materials on different groups of children leaners such as children learning Chinese as a second language, instead of the target learners that the book series has set on. The finding from the initial evaluation indicated a low score of 91 in individually evaluated categories except one, which is being systematic. Categories in being specific, being practical, being scientific, and being intriguing all received a low score. The current surmise is that the then Children's Chinese Reader is a synchronic product of its time that now calls for advancement in latest theoretical research and contemporary teaching principles if materials for children's learning can play an appropriate role in modernday teaching.
\end{abstract}

Keywords: content analysis, teaching Chinese language to children of other languages (COL), COL textbook, textbook evaluation 
Introduction

In 2006, the US government announced AP Chinese courses and the related test regulations. This act dramatically expanded the learner range; as a result, Pre-AP Chinese begins to boom, a prep course that allows children and teenagers to have a seamless transition into a more advanced Chinese course in high schools (Chiu, 2017; Yeh, 2010). The tendency of learning Chinese also encourages celebrities' family to scramble for it. For example, A. Kushner, the 10-year-old granddaughter of the Former American President D. J. Trump, and two daughters of the American investor and financial commentator J. Rogers, performed Chinese song singing and reciting The Three Character Classic and even Tang poetry. Ever since their performance clip went viral, the topic on children's Chinese learning has once again become all the rage and rekindled enthusiasm in this field of research.

In early days, teaching overseas children Chinese is a matter of mother tongue teaching. For this purpose, Children's Chinese Reader published by the Overseas Community Affairs Council (OCAC) is the primary textbook. It has twelve volumes, developed by experts and scholars in 1993 and targeting at Grade 1-6 overseas Chinese children, and has since become one of the classical textbooks in Chinese learning and teaching. Textbooks largely determine not only what topics and ideas are taught in the classroom but also the way they are presented to students, so textbooks affect learning and teaching in many different ways (Stern \& Roseman, 2004; Behnke, 2018). After twentyfive years of use, an evaluation is in order if one wants to know whether the exact materials can still meet the modern demand and can serve its proper role in the NorthAmerican Pre-AP course. With this research aim in mind, this study shall focus on content analysis.

\section{Literature review}

Undeniably, the developed standards and assessment indicators of language textbooks in research and practice have established general rules that appear to be applicable to assess the digital and paper textbooks, with some of them specific to other subjects and users depending on developers' research interests (Bouzid, 2017; Cai, 2021; Mahmood, 2011). Combining with viewpoints of Liu (2002) and Zhao (2005), Wang (2008) proposed six major categories to be the basic structure for assessment indicators of Chinese textbooks for children of other languages (COL): background, specificity, 
practicality, scientific-ness, engagingness, and systematic-ness.

Background

It is incumbent on the textbook writer to draw in his linguistic expertise, relevant theories and pedagogy to complement the content. Learners' cognitive development also dictates the textbook's learning focus. In addition, the importance of editing and compiling materials goes without saying because of its impact on both teaching and learners' learning outcome. The corollary of writing up a textbook for Chinese learning must take into consideration the learning goal and leaners' mental process.

\section{Specificity}

The quality of teaching materials directly affects learner' efficiency. In textbook compiling, it is necessary to analyze target users' various specificities, such as age, nationality, social-cultural backgrounds, and Chinese proficiency, so that a distinctive textbook for specific readers can be completely developed. Specificity is not only the most important principle in textbook compilation, but also the basis for embodying other principles, a fact that widely (Cai, 2021; Education Bureau of Hong Kong, 2016; Li, 2002; Smart \& Jagannathan, 2018; Xu, 1992).

\section{Practicality}

There is still no precise definition of practicality toward teaching materials. Wang (2018) believes that the practicality principle plays two roles, one is content practicality; the other method practicality. The content must be based on the learning needs, immediate application to real life, and adaptability of techniques and principles in various language teaching. In addition, criteria related to the learning practicality should be considered for language textbook evaluation (Czerwionka, 2015). According to Mustami et al. (2019), both students and teachers will have a positive response to the teaching material if teaching materials are practical.

\section{Scientific-ness}

Scientific-ness is one of the important indicators for evaluating the quality of Chinese language textbooks (Dong, 2017; Guan, 2020; Tsai \& Shu, 2017), and compiling Chinese language textbooks at all levels should follow this principle ( $\mathrm{Li}, 2010)$. Scientific-ness presents that words should be standardized and universal. For example, 
男大生 and 女大生 often spoken in Taiwan, mean male/ female university students. Nevertheless, such vocabulary may be not understood by native Chinese speakers in other areas than Taiwan. Therefore, local words are not recommended to be written in language textbooks. Secondly, the organization of the content should conform to the rules of language teaching. The so-called conformity to language rules means that content is required to be from simple to complex, which is also in line with the ' $\mathrm{i}+1$ ' assumption in the natural approach. New words and grammatical points in each lesson should be evenly distributed; a sentence, especially in the elementary textbooks, should not have two new words or two new grammatical points. The recurrence rate for new words and grammatical points taught must be also considered for the compilation of textbooks to strengthen L2 learners' memory.

\section{Engagingness}

The so-called engagingness is that textbooks and teaching should be lively and interesting (Chen, 2014; Tsai \& Shu, 2017; Guan, 2020). An interesting language textbook embodies in content and layout (Guo, 2012). The self-relevant content can interest learners, and colorful and clear illustrations can appeal to their attention. Child psychologists believes that arousing children's strong interest is a way of facilitating their autonomy to learn. Guo (2012), Ma (2005), and Xu (2009) have emphasized the importance of engagingness in compiling Chinese language textbooks. For children, happy learning producing happy mood is the first condition in the process of acquiring a foreign language.

\section{Systematic-ness}

The systematic content for a Chinese language textbook, horizontally, not only considers Chinese language knowledge, such as phonetic, vocabulary, grammar, Chinese characters, Chinese culture, and other language points, but also has equal opportunities to train four language skills: Listening, speaking, reading, and writing; Vertically, perfectly connecting textbooks in zero, elementary, intermediate, advanced levels is necessary (Guo, 2017). Additionally, a systematic Chinese language textbook should be paper-printed and online-format, and provides teachers and students with teacher manuals, workbooks, and test papers (Li, 202; Li, 2016). Huang (2010) stated that textbooks are the knowledge device on which teaching and learning are based, and lesson plans and syllabuses is close to units of textbooks (Huang \& Huo, 2005). Only 
when compiling textbooks, taking system as the soul of textbook compilation can meet the requirements of learners from different countries and with different goals (Liu, 2002).

Research method

The content analysis was used to evaluate the Children's Chinese Reader by Wang (2008)'s assessment based on Liu (2002) and Zhao (2005). Six major categories were separated as the basic structure for assessment: background, specificity, practicality, scientific-ness, engagingness, and systematic-ness. Out of these categories, forty descriptive items were generated with a scale of four points in each item. The final score was the average point of all items and was calculated after eight reviewers in this study had examined all twelve volumes.

However, certain wording that sounds subjective and overbearing in the original form needs revising before a fair and objective review can be carried out. Most authoritative tone of expression has been replaced with positive statements which shall facilitate our objective evaluation and provide comprehensive constructive suggestions on how to improve the current materials under study as well as other similar materials.

Results and discussion

Background

Table 1 is the itemized result, with description on the left and point on the right.

Table 1 Scores in background

Items $\quad$ Scores

Compiling with linguistic and learning 3

theories

Resorting to one or several teaching 4

method

Based on the Chinese linguistics and 4 
culture

Compiling with the lesson plans and 2

syllabus

Satisfying with the psychological process 2

of learning

Compiling with linguistic and learning theories

Although a good number of theory proposals and research findings on second language acquisition come from studies on learning English as a second language, two theoretical perspectives are relevant in counting for language learning in general.

According to cognitivism, meaningful learning takes place if what is newly learned can be related to learners' previous knowledge. (Li 2000) Likewise, the tripartite learning processes: action learning, image learning and symbol learning, perceived by the renowned cognition psychologist J.S. Bruner, co-exist in a unique and complementary manner in shaping learning. (Chiu, 2014). J. Bruner once said, "Knowing is a process not a product.", claiming that the goal for learning is not about remembering what has been taught but about knowing the process of how to construct one's knowledge (Zeng, 2010). To achieve this goal, a teacher's primary task is to provide a learning scenario for students to actively explore and to grasp underlying concepts and principles. (Shao, 1997)

According to the American developmental psychologist Gardner's theory of multiple intelligences, there are eight specific modalities of intelligence: musical-rhythmic, visual-spatial, linguistic-verbal, logical-mathematical, bodily-kinesthetic, interpersonal, intrapersonal, and naturalistic. Apparently, Chinese learning and teaching aims to develop learners' verbal intelligence in acquiring all key components in mastering Chinese as a proper language. (Qiu, 2014)

An evaluation of dialogues and texts by considering the relevant theories discussed above being applied ends with an average score of 3 points. This score is slightly beyond the actual theoretical appeal.

Resorting to one or several teaching method 
In this century, new teaching methods have been updated from time to time due to a plethora of related research. It is not enough to emphasize the importance of teaching methods because of a closely intertwined relationship among methods, material design, teaching, proficiency, and testing. (Lu, 1994)

The Grammar-Translation Method, the earliest and traditional language teaching mothod, enables L2 learners to read and translate texts written in the target language, and to further L2 learners' general intellectual development (Valencia et al, 2008). L2 learners' reading comprehension through the grammar-translation method concludes that their reading comprehension through grammar translation improves significantly (Kurniawan et al., 2020; Megawati, 2017). This why that almost all Chinese textbooks but the Children's Chinese Reader have word banks, grammar and patterns, and translations, undeniably, influenced by the Grammar-Translation Method.

The main texts from the 1st to 7th volumes of the Children's Chinese Reader are dialogues. In the exercises, sentence patterns drills distribute in all volumes of the Children's Chinese Reader. The characteristics of the Audiolingual Method include materials presented in dialogue form and structural patterns taught using repetitive drills (Valencia et al, 2008; Larsen-Freeman \& Anderson, 2011). The Children's Chinese Reader, therefore, is consistent with the Audiolingual Method. The main texts transmitted from dialogues to short-texts from the 8th to 12th volumes of the Children's Chinese Reader are concert with the reading approach, created by West (1937), a founder of teaching reading methodology (Abdune'matovna, 2020). The reading approach believes that the first goal of second language learning is to cultivate learners' reading ability, of which method allows learners to promote the target language sense without translations through a lot of readings, followed by oral work and training in speech (Zhou, 2017).

Based on the Chinese linguistics and culture

Language is a part of culture and an important carrier of culture. When people learn or use a language, their words and deeds will naturally reflect the culture represented by the language, and even comply with the social and cultural norms. However, people from different cultural backgrounds often lack understanding of the cultural background of the target language, which can easily cause communication difficulties. Cheng (1991) believes that introducing culture in Chinese language classes aims to 
eliminate cultural barriers in the communication between native Chinese speakers and non-native Chinese speakers, and overcome the communication difficulties caused by differences in cultural factors, thinking patterns, values, and moral ethics. The compilation of the Children's Chinese Reader is based on Taiwan-relevant situations. Although some of the vocabulary is not close enough to the language habits of the Taiwanese people, most content focuses mainly on Chinese culture and society.

Compiling with the lesson plans and syllabus

According to Chiu's study (2017), the version issued by The Overseas Community Affairs Council in 2009 is written following three major principles which are (1) Grade 1-9 Curriculum of English, (2) CCCC level indicators, developed in 2006, and (3) The ACTFL Guidelines, developed in 1996.

Yet, the version under current study is the first version issued in after July, 1993 and get revised in June, 2005, a timeframe way earlier than the principles mentioned above are adopted, and little lesson plans and syllabi are found in teacher manuals. Hence, the score is 2 points after assessment.

Satisfying with the psychological process of learning

Compared to adults, children are characterized with a developing mental state and cognitive ability. Therefore, language learning is an ongoing and cumulative process. In Lin's (2003) viewpoint of educational psychology, the psychological process of learning means children's cognitive development which comes from their adaption to the environment and their assimilation of information. Piaget and Vygotsky, two pivots in cognitive development research, according to Wang's online vocabulary list (2000), offer much insight. In Piaget's theory, the four stages - sensory-motor, pre-operation, operation and formal operation - accord with children's cognition development. In Vygotsky's theory, social and cultural factors matter. Children learn about culture via talks with adults and via formal education. "Scaffolding" refers to the support children receive and then act as expected.

The current textbook review, checking against the insight discussed above, finds only the presentation of grammatical points slightly obey the supposed development observed in children. The assessment score is 2 points. 
Table 2 is the itemized result, with description on the left and point on the right.

Table 2 Scores in specificity

Items $\quad$ Scores

Fits learners' age, ethnicity and culture 3

Fits learning goal 3

Fits learners' present language level 2

achievable goal given the time for 3 learning

What can be concluded from Table 2 is given in detail below.

In the first descriptive item, all twelve volumes can be used in good order throughout Grade 1 to 6 . In particular, the way short passages, festive topics and the origins of idioms are introduced from volume 7 and onward makes learners become better aware of Chinese culture as language learning continues.

The second description in Table 2 also gives approval to the content because learners begin with basic everyday vocabulary and topics. And the learning moves on step-bystep to more advanced level.

In the third description, the strength lies in the convenience for learners to review and to read because of accessible pinyin printed in the text. However, certain vocabulary appears futile in use (Figure 1). The other drawback is an overcrowding of dialogues, though divided into 4 short sections (Figure 2), could go beyond non-overseas Chinese learners' learning capacity. 
2.生字生詞 (Vocabulary \& Expressions)

第

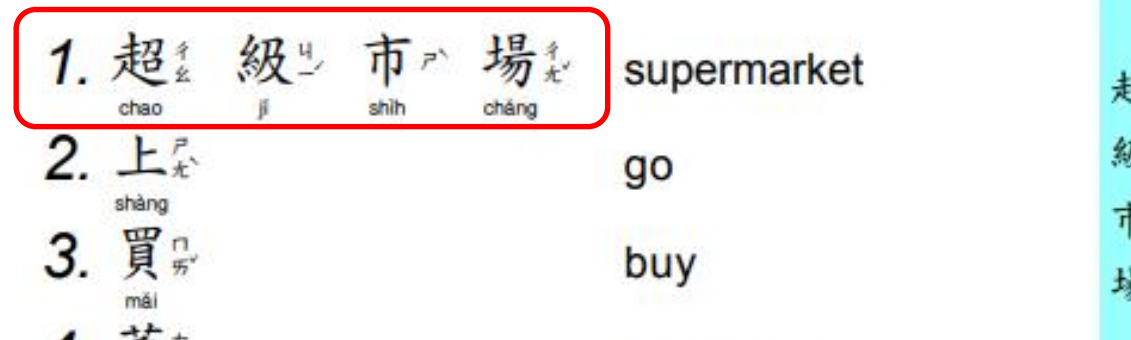

超

級

市

場

4. 菜索少 food; dish

5. 二兀十户 twenty

6. 張峞

(measure word)

7. 優文 待唯 券出 coupon

8. 些要 some

9. 豬出肉最 pork

10. 雞 肉最 chicken

11. 火宏 腿素势 ham

12. 熱昆狗吕毛 hot dog

13. 跟《 and

14. 魚 fish

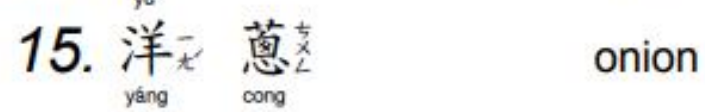

Figure 1 Samples for outdated vocabulary 


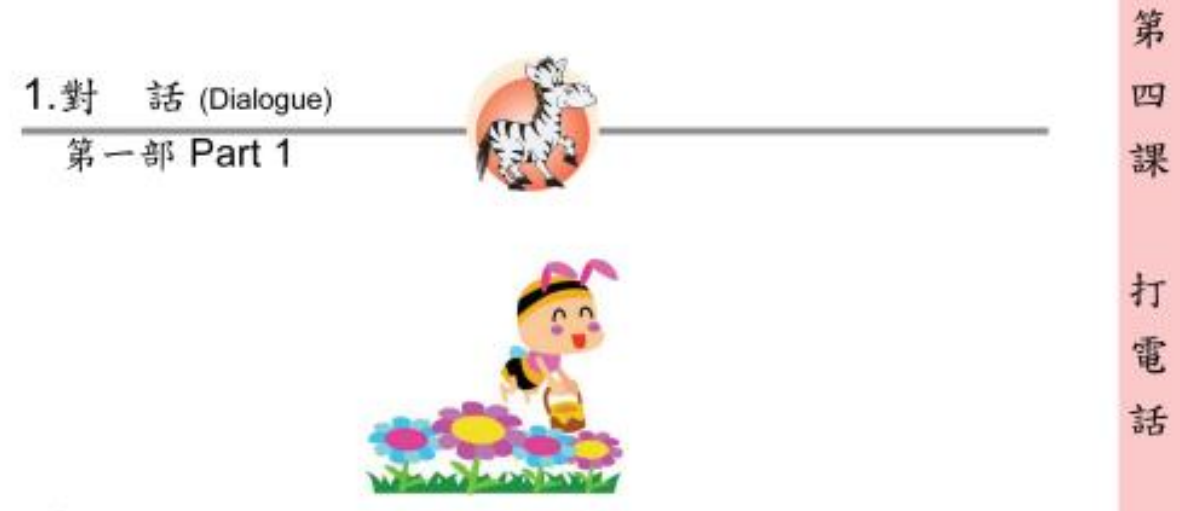

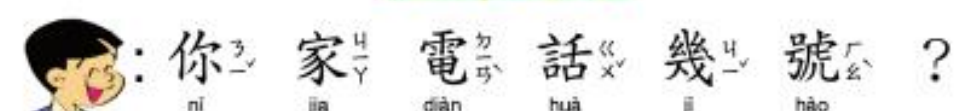

y.

你等家芦的案呢案?

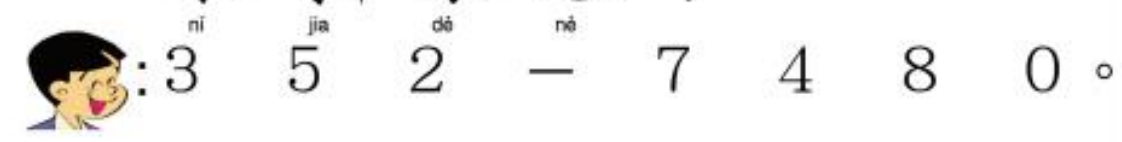

第

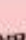

打

電

話

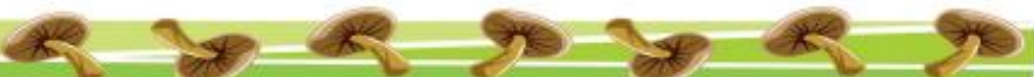




\section{第二部 Part 2}

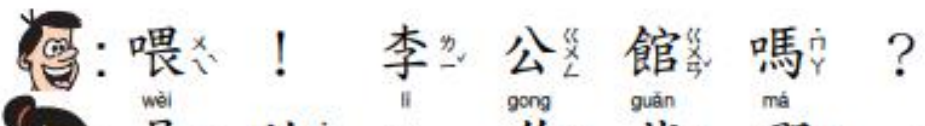

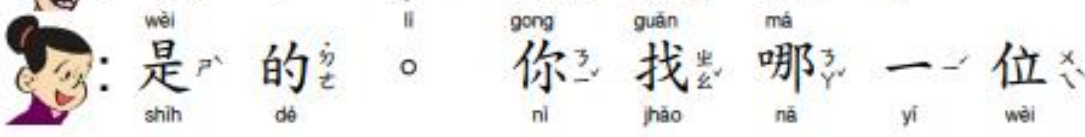
?

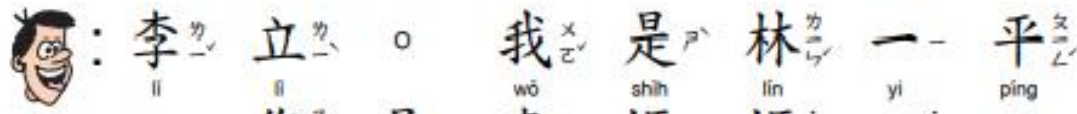

。您是李媽媽吧?

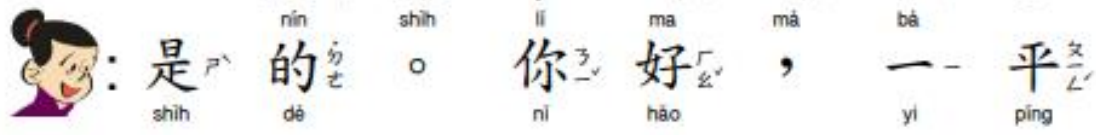

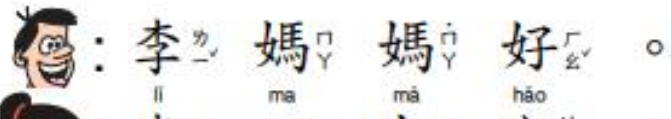

Q

下年。

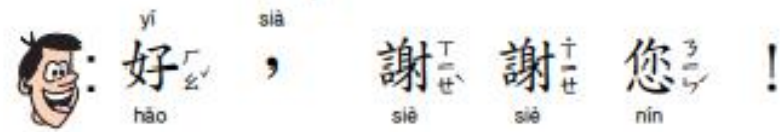
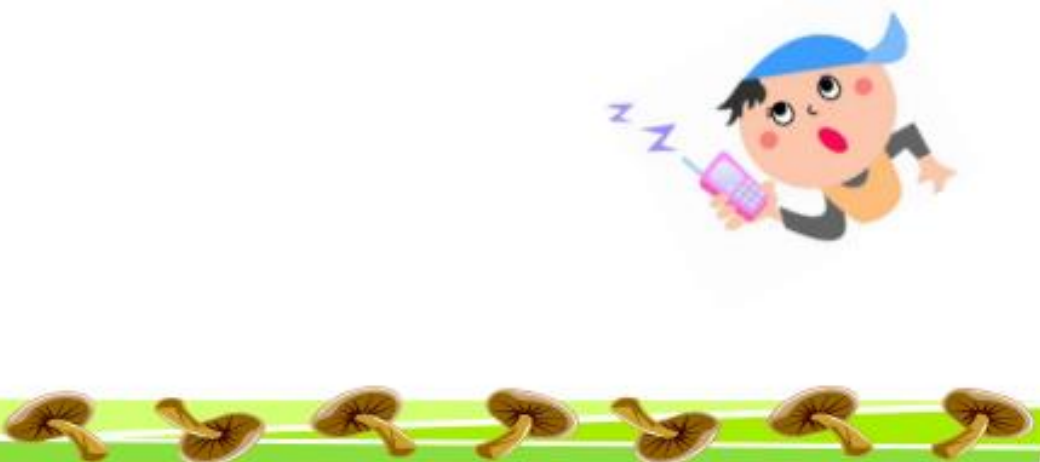
第三部 Part 3

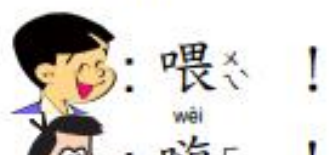

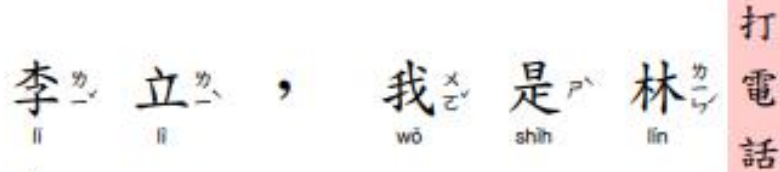
- - 平文

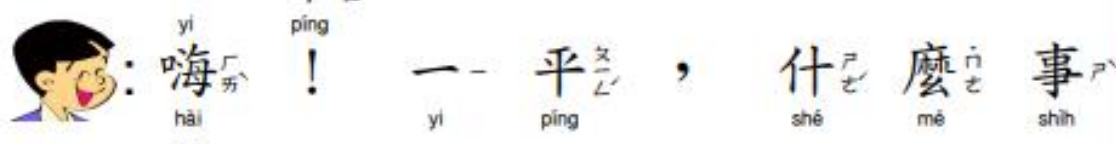

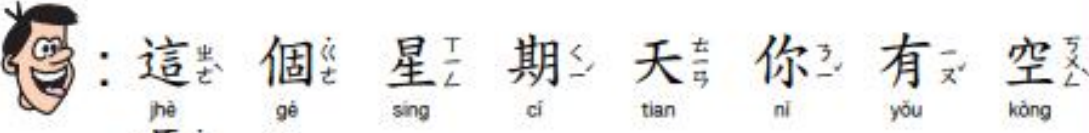
嗎宇?

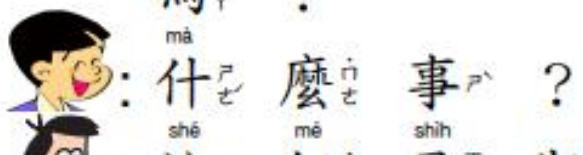

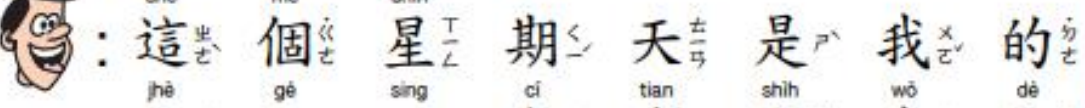

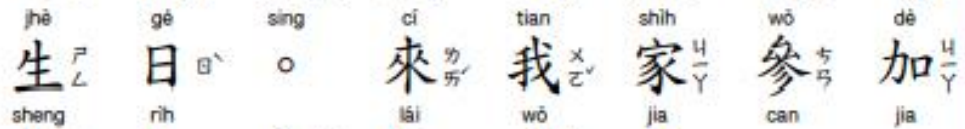

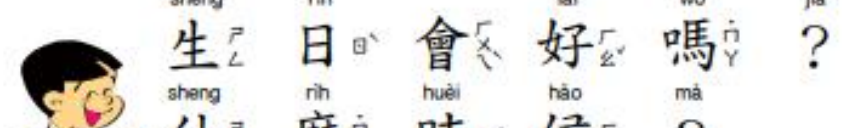

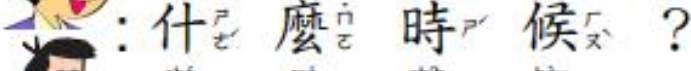

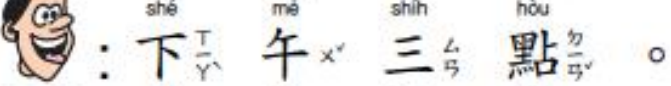

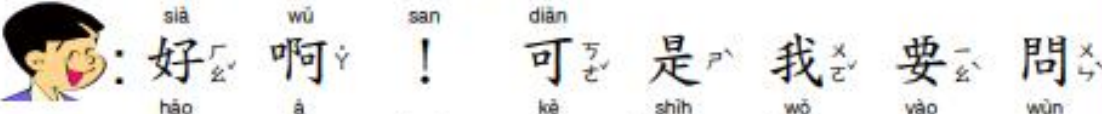

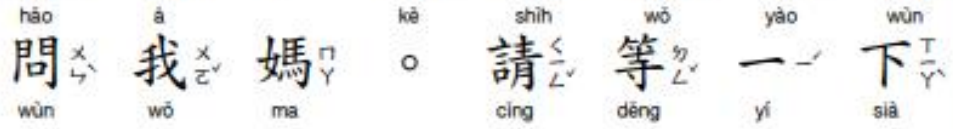
。

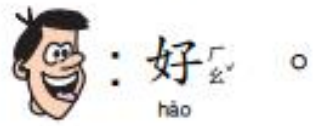




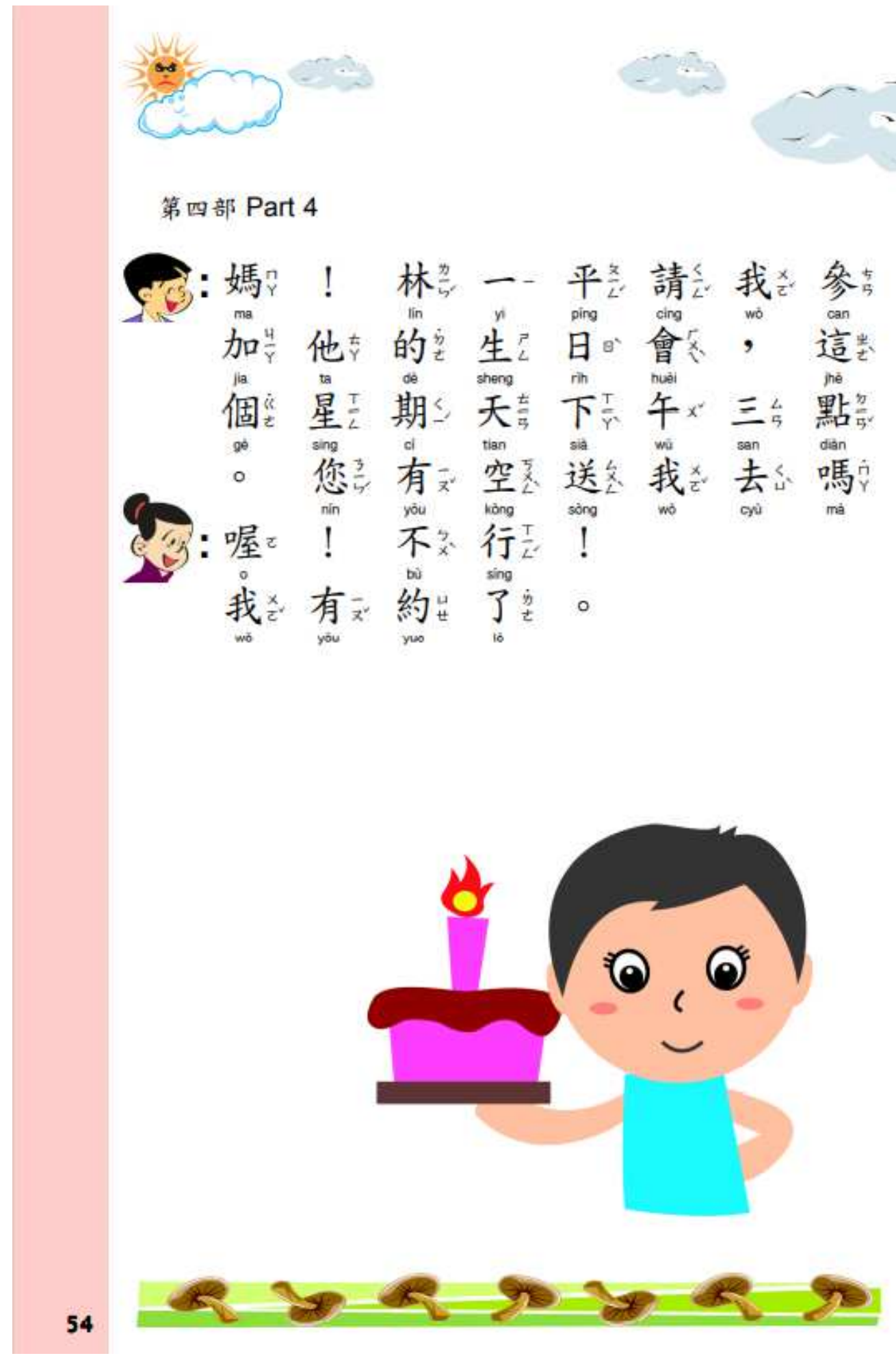

Figure 2 An overcrowding of dialogues

In the last description, the tricky part is many external factors can delay the time needed to achieve the learning goal, one factor being a teacher's choice on the hours or activities s/he needs to finish learning a lesson. 
Practicality

Table 3 is the itemized result, with description on the left and point on the right.

Table 3 Scores in practicality

\begin{tabular}{ll}
\hline Items & Scores \\
\hline Learners' reality needs are met & 2 \\
\hline Authenticity & 2 \\
\hline $\begin{array}{l}\text { Appropriateness in both written and } \\
\text { spoken mode; dialogues reflecting reality }\end{array}$ \\
\hline $\begin{array}{l}\text { Materials for rote learning right from the } 3 \\
\text { beginning }\end{array}$ \\
\hline
\end{tabular}

Connecting new ideas with the old ones 2

Plenty of practice for practicing four 3

skills

Comprehensibility, mechanicalness, 2

applicability

Various types of exercises 1

Taking into account the training of four 2

language skills

Moderate amount of vocabulary in each 2

lesson and the sufficient recurrence rate

Opportunities for learners to self- 1 
evaluate

According to the foreword of the Children's Chinese Reader, the textbook is initially designed for overseas primary school students to be able to strike up conversations that reflect their daily routines such as brushing teeth, putting on uniforms, finding out what to eat for breakfast, or asking for permission to drink chocolate-flavored milk instead of the formulaic greeting exchanges written in the textbook. The greeting dialogues in Lesson 1 (Figure 3) raises doubt on whether learners' learning needs are met or not. 


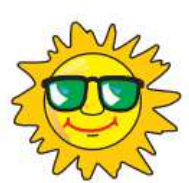

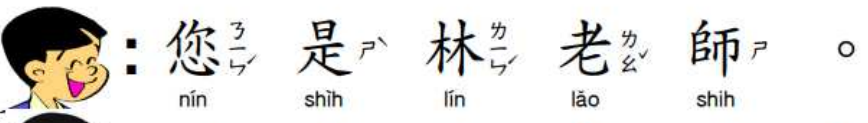

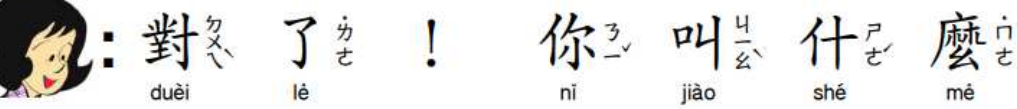

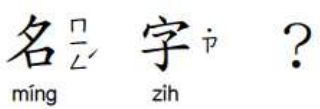

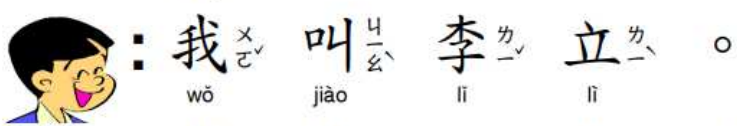

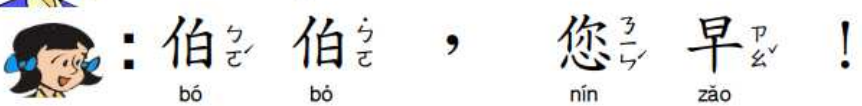

: 你了 早品 !

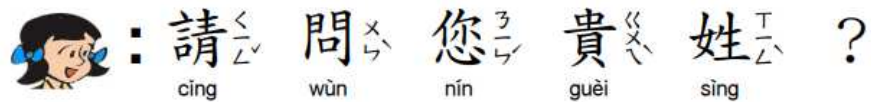

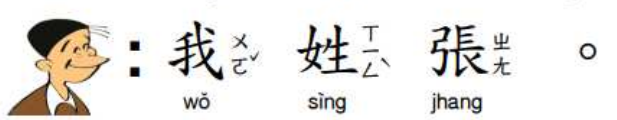

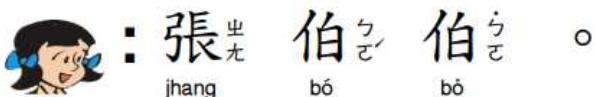

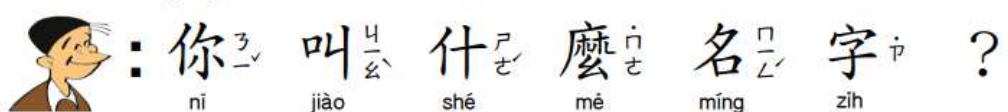

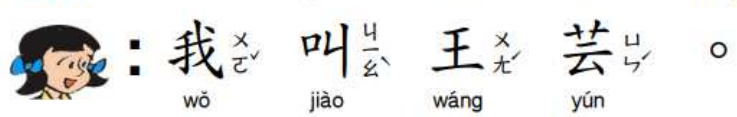

(Ding Ling! The bell rings.)

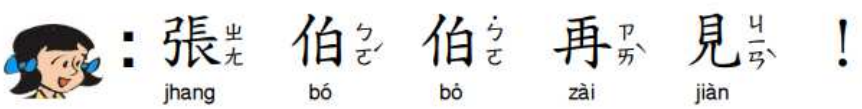

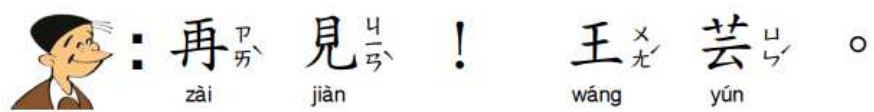




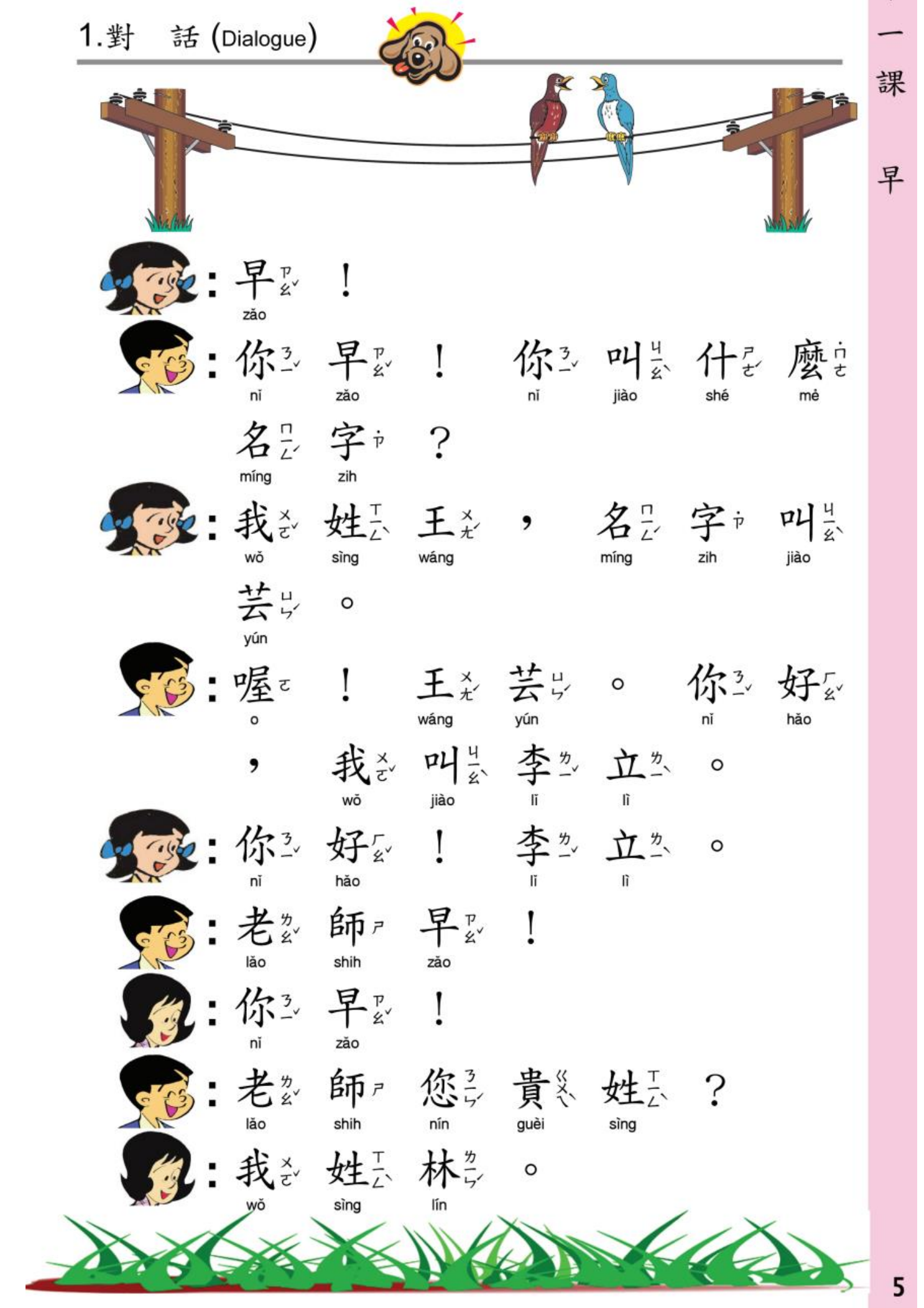

Figure 3 The greeting dialogues in Lesson 1, Book 1 The greeting exchanges in Lesson 1 also lack authenticity because greeting usually 
occurs between acquaintances, not people who meet for the very first time. The greeting the little boy exchanges with the little girl and with the teacher is both not authentic and illogical (See Figure 3). Another similar example can be found in dialogues having to do with children's doing role assignment in a baseball game (Figure 4). A dispute-free conversation goes against one's understanding of children's competing for having the say of which role each person should take. 


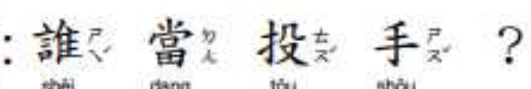

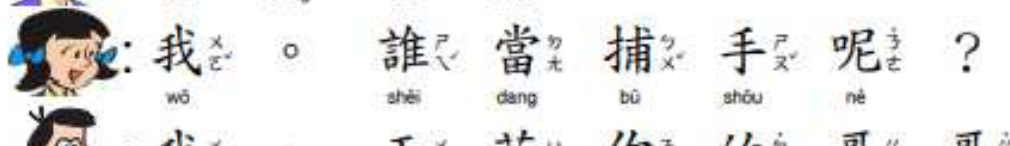

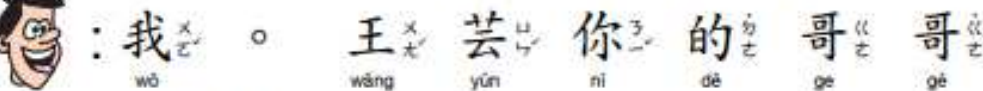

, 姊出

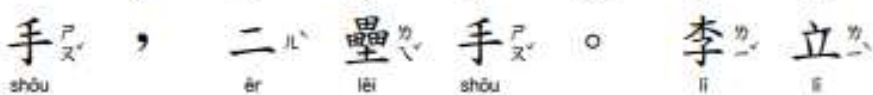

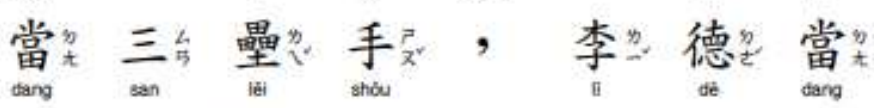

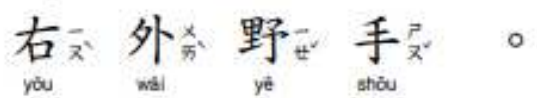

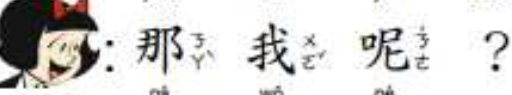

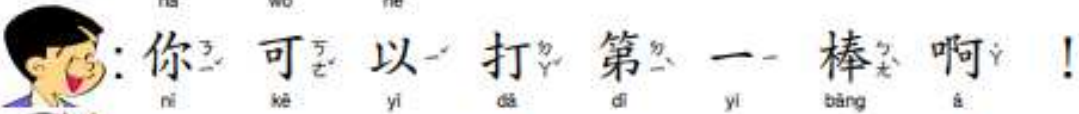

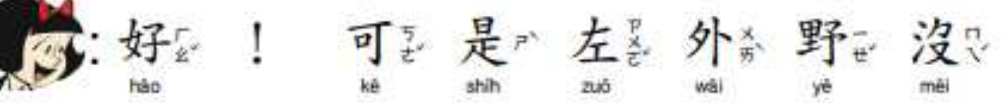

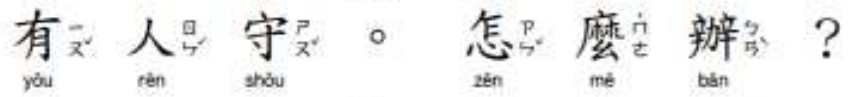

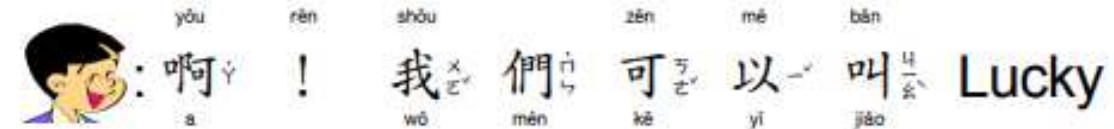

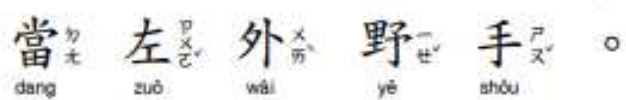

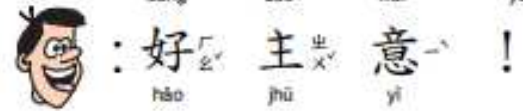




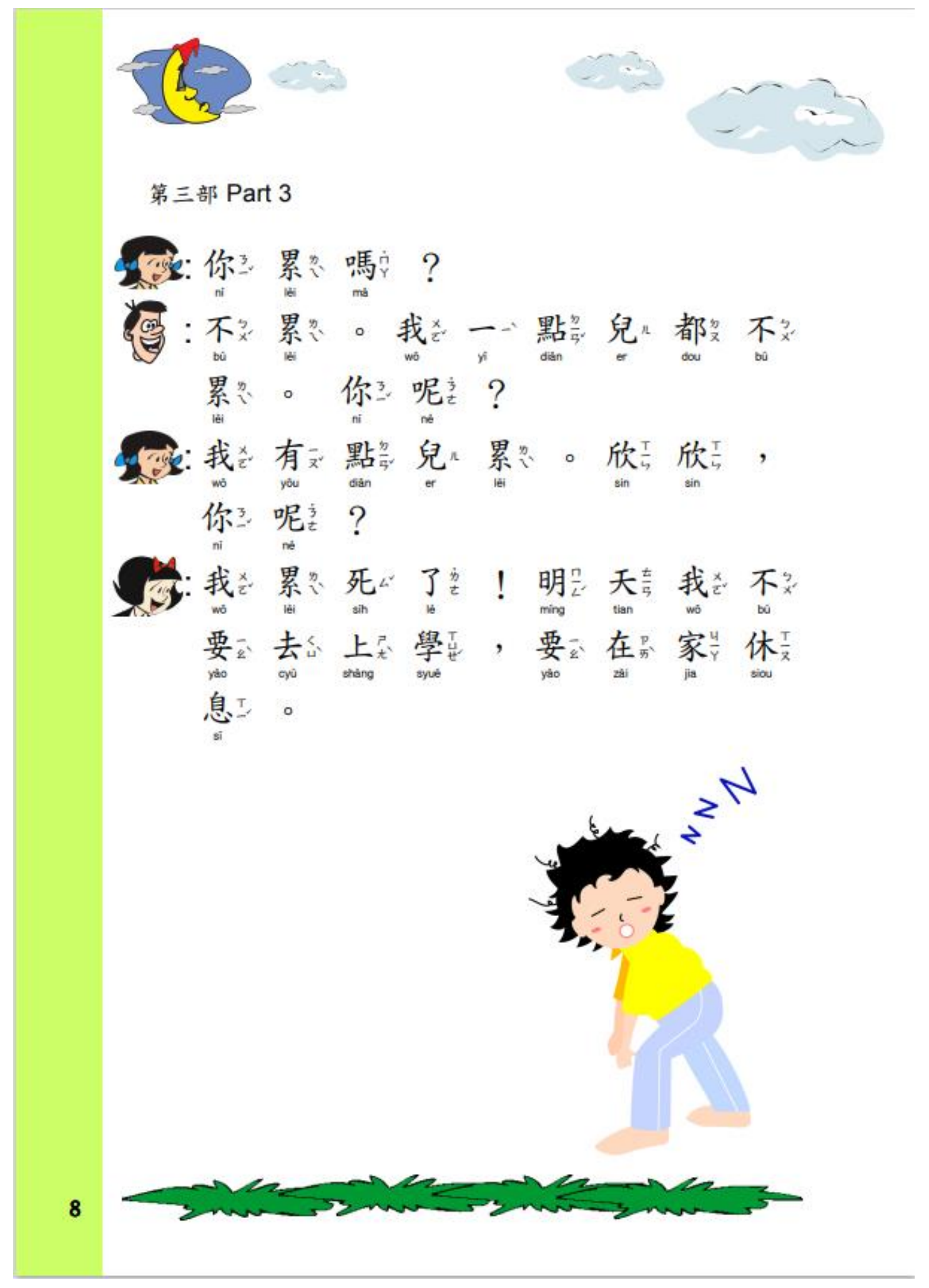

Figure 4 The dialogue for baseball game in Lesson 1, Book 5

In Figure 3, the little boy greets the person he doesn't know, and greets the teacher he knows, but then asks for his teacher's surname. Surprisingly, the teacher does not know his name and ask what it is. Unreal dialogues not only appear in this lesson but also in 
other lessons. The content may fit pedagogical grammar but loses authenticity.

The texts in Children's Chinese Reader are not long, so they are suitable for children to learn by heart. And nursery rhymes may be even better for children to learn.

Evaluation on this item is difficult because of its early publication. What can be observed is a gap between the old-fashioned use of vocabulary back then and the current use. Topics such as smart phone, internet, iPad, and artificial intelligence (AI), are hard to find and should be added in the future.

The Children' Chinese Reader is accompanied by teacher's manuals and workbooks. Games and activities are introduced in each lesson in the teacher's manual, so students can have enough practice and learn happily following the teacher's guidance.

Most exercises are mechanical drills, fitting the concept of the audio-lingual method. For example, the exercises (Figure 5) in the workbook for Lesson 1, Book1 are substitution drills to strengthen students' speaking ability by substituting with alternative words and sentences. Nevertheless, few practices involve comprehensibility and applicability. Teachers using this textbook must spend time supplying a variety of exercises for COLs. 
IV Fill in the blanks.

1. A： 早趾!

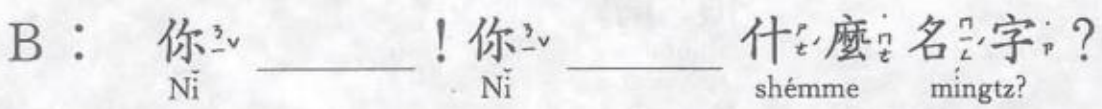

2. A：老螄 您

?

B：我姓王王。

Wõ shing Wáng.

3. A：伯产伯高—早趾!

B：你ㄴ.早趾!

Nì tzău!

4. A：你叫叫出什

$\mathrm{Ni}$ jiàu shémme

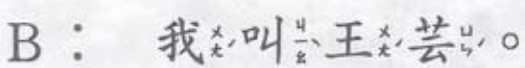

Wõ jiàu Wáng Yún. 
5. A： 林并老距, 再?

Lin lảushr tzài

B :

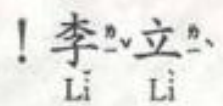

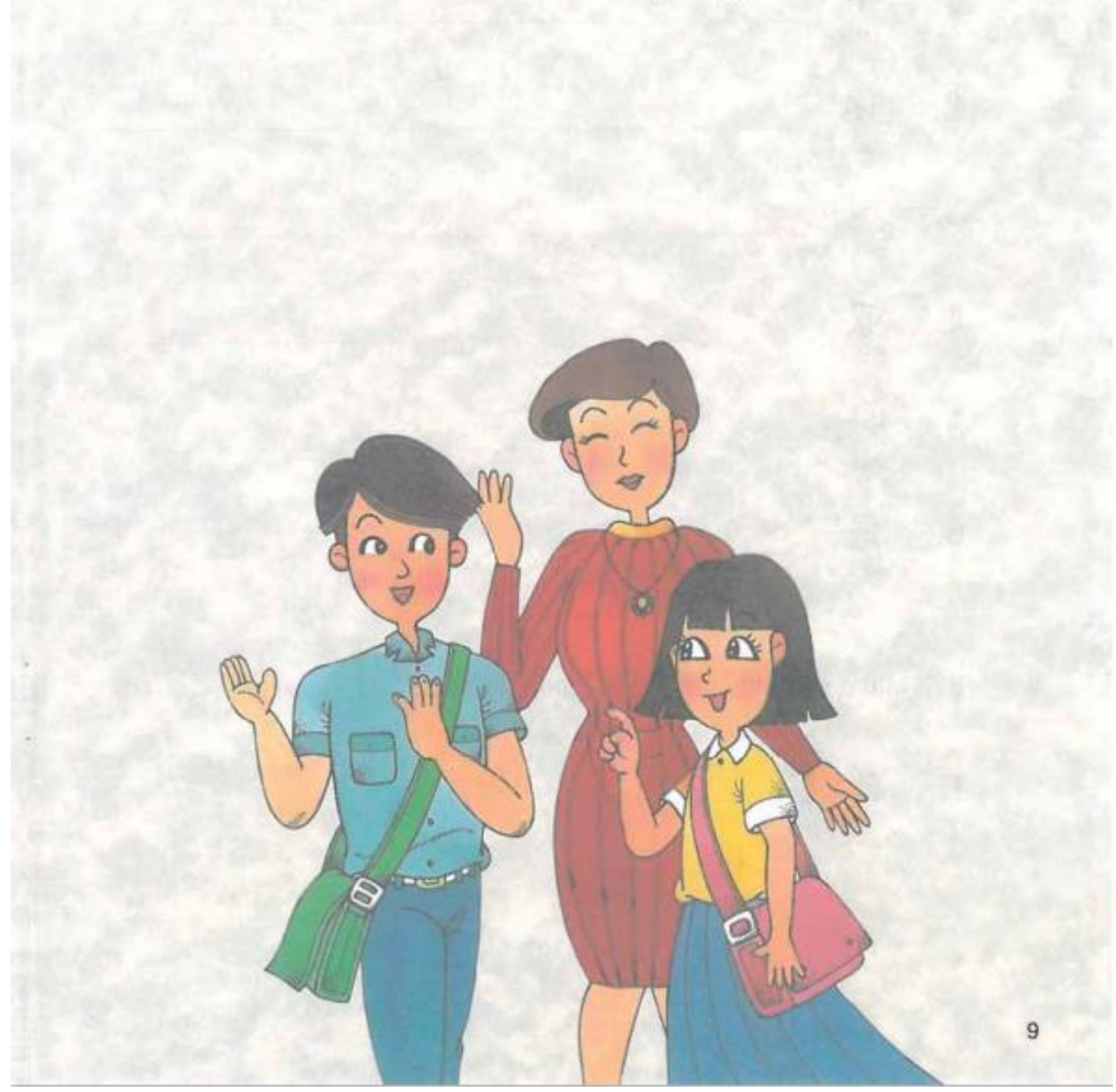

Figure 5 The exercises in the workbook for Lesson 1, Book1

The exercises found in the workbook, in most cases, are fill-in-the-blank sentences that are directly taken from the dialogues in the main text. Doing it may reinforce the recognition of the characters but may fail to develop student's thinking ability. Therefore, the evaluation score is low. 
The Children's Chinese Reader has dialogues, vocabulary, pattern practices, Chinese characters writing, and Chinese characters and sentences reading textbook. However, it will be better to provide teachers and students with videos and audios for listening practices.

Compared with 15 Chinese characters and 20 words distributed in each Chinese lesson that is learned by elementary school children in Taiwan, 21 new words (Figure 6) in Lesson 1, Book 1 of the Children's Chinese Reader are a little too many for COL beginners. However, the high recurrence rate of new words in each lesson is beneficial for COLs to have more opportunities to learn repeatedly. 
1. 早

Good morning!

早

2. 你

you (singular)

3. 叫奚

my name is... I'm...

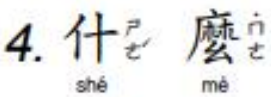

what

5. 名 $\frac{n}{\text { ming }}$ 字i (p) name

6. 我

I, me

7. 姓志

family name, last name

sing

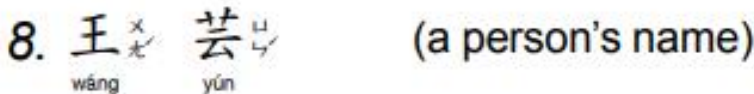

9. 喔こ (exclamation) Oh!

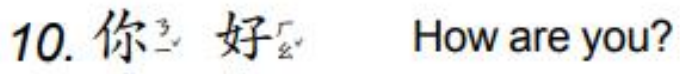

11. 李为 立为 (a person's name) 


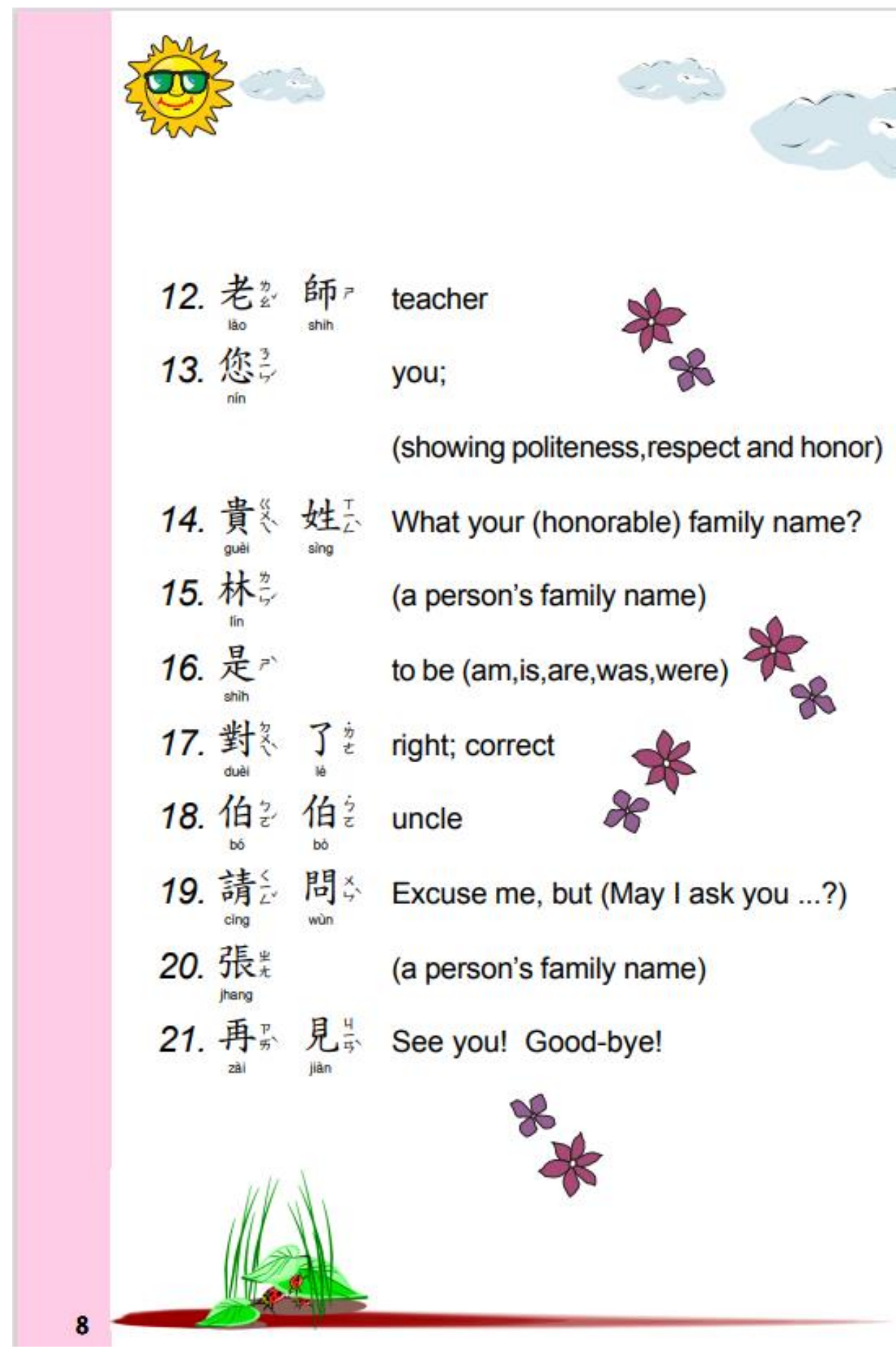

Figure 621 new words in Lesson 1, Book 1

Workbooks provide only exercises for practice but no answer key for COLs to check. This may foil students' motivation to monitor his own learning and decrease the opportunities for self-evaluation. That is, they have to rely on teachers' or parents' guidance to find out if their answers are correct. 
Scientific-ness

Table 4 is the itemized result, with description on the left and point on the right.

Table 4 Scores in Scientific-ness

\begin{tabular}{l}
\hline Items \\
\hline Prescriptive and widely circulated use of 2 \\
language \\
\hline Following the official guideline of 2 \\
COL's Chinese proficiency and the \\
recommended vocabulary list with \\
contexts for children's Chinese \\
competency certification (CCCC)
\end{tabular}

In line with the principle of language 3

learning: From simple to difficult

Keeping up with latest theoretical 2

research and updating the content in time

Correctness in linguistic explanation $\quad 2$

Translation accuracy and readability $\quad 2$

Correct sentences 2

Appropriate layout and illustrations $\quad 2$

Correct punctuation marks $\quad 1$

What can be concluded from Table 4 is given in detail below.

Prescriptive use of vocabulary, sentence patterns, dialogues, and texts in this textbook 
can be observed, but the use is not even close to Taiwanese speaking styles. For example, words for direction, such as $「$ 上邊兒」"upside"、「下邊兒」"below"、「裡邊」"inside", and $\ulcorner$ 外邊」"outside", are often rendered as $「$ 上面」「下面」 instead by Taiwanese people. $「$ 華埠」"Chinatown" in Lesson 12 of Book 10 is another example of failing to use the much more familiar term $\ulcorner$ 唐人街」 or $\ulcorner$ 中國城」

The official guideline for Chinese proficiency in Taiwan, based on the Common European Framework of Reference for Languages: Learning, Teaching, Assessment (CEFR), was announced in 2003, and the recommended vocabulary list with contexts for children's Chinese competency certification (CCCC) was developed in 2009. In the United States, the Standards for Foreign Language Learning in the 21st Century was developed by the American Council on the Teaching of Foreign Languages (ACTFL) in 1996, and the Goals and Standards for K-12 Chinese Language Learning was included in 1999, which provided COLs with clear goals and norms to learn Chinese. However, the Children's Chinese Reader, published in July, 1982, and revised in June, 1994 , is earlier than the official guidelines, so the present vision is not compiled based on any official guidelines of Chinese proficiency.

Dialogues are presented from Book 1 to Book 7, and instead of dialogues, short texts are presented from Book 8 to Book 12. Spoken language is presented first and then followed by written form. Exercises also follow the principle of language learning: from simple to difficult.

In recent years, the increasing research on language teaching methods and materials has conducted, but the Children's Chinese Reader has not been revised even a little bit since 2005. Although there are electronic versions available for teachers and learners to download and use, the content stay frozen failing to conform to the trend of the times.

According to J. Piaget's theory and stages of cognitive development in children, it is understandable that explanation of grammatical structures in the Children's Chinese Reader is seldom found. Ironically, tone marking mistakes and typos go unnoticed. In terms of cultural knowledge, no cross-cultural differences are discussed for COLs. What is found is a simple mention of women having their husbands' surnames after marriage in Lesson 3 of Book 12, parents' being obliged to arrange marriages for their children, the concept of the 'excellent match in position and in wealth' for marriages, 
and the concepts of modern people falling in love and getting married under the influence of western thoughts.

The Children's Chinese Reader uses English as the auxiliary language, but the vocabulary translation is not uniform. In terms of polysemous vocabulary, some words receive multiple interpretation in the translation; others are translated with the intended meaning in the lesson. Moreover, still others have questionable translations. For example, in “林老師說：「對了! 你叫什麼名字? 」’, 'Right. What's your name?’ is the English here. Yet, '對了' in Lesson 1, Book 3 is 'Oh' in English.

Consider sentence pattern exercise No. 4 in Lesson 3, Book 6: 「我希望爸爸買一個活 動房屋」 "I hope my father buys a mobile home". Obviously, the measure word for the house is used incorrectly. Now consider sentence pattern exercise No. 4 of Lesson 4, Book 5: 「媽媽要上學、買菜, 還要洗衣服」"Mom has to go to school, buy groceries, and wash clothes." Although "Mom goes to school" is possible, generally speaking, most ef mothers go to work, not go to school. Using 上班 'go to work', instead of 上 學 'go to school' is more reasonable. In addition, there are also obvious errors on page 75 of Book 7: 「我喜歡吃_的蔬菜和水果」"I like to eat vegetables and fruits " (Figure 7). The correct answer is 新鮮, but '鮮' in the answer option is incorrect. 


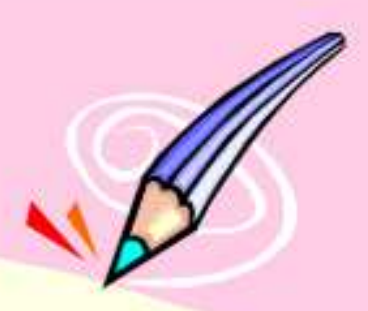

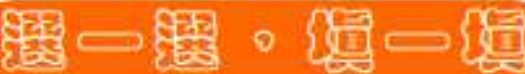

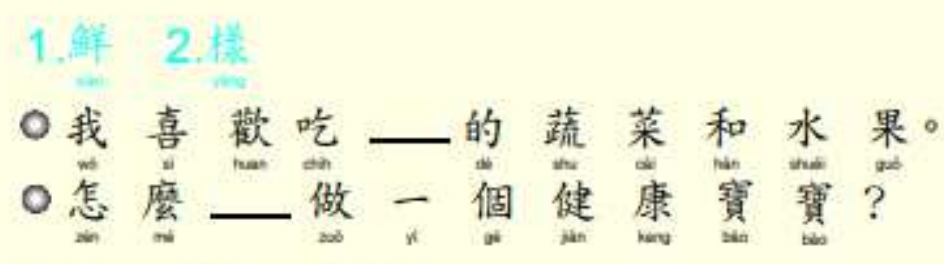

1.遗 2. 辛 3 . 得

○電影明星都打扮—很漂亮。

○吃—東西要刷牙。

○爸爸最近忙—安排面談。

1.看起來 2 . 脰

○那塊蛋糕—好香!

○這些玫瑰—惩很意。

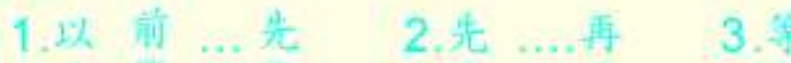

○我們要——洗手, — 吃飯。

○吃飯—, 我們要—洗手。

○_我們大家都洗了手,

一開始吃飯。

Figure 7 A sample for obvious error

In the teaching of radicals and stroke orders, words are illustrated, but no blanks for COLs to practice writing (Figure 8). Main texts in the textbook are marked with Hanyu pinyin and Chinese phonetic symbols, but only Chinese phonetic symbols are found in workbooks. What is worse, the marked phonetic systems are not consistent. Words that 
should be marked with Chinese phonetic symbols are marked with pinyin instead. (Figure 9).

\begin{tabular}{|c|c|c|}
\hline \multicolumn{3}{|c|}{$\begin{array}{l}\text { Let's learn how to write Chinese characters. } \\
\text { Please follow the stroke order and write each one ten times. }\end{array}$} \\
\hline $\begin{array}{l}\text { 生字及 } \\
\text { 注音 }\end{array}$ & 部首 & 筆順 \\
\hline 自 $>$ & 自 ${ }^{n}$ & '门白自自 \\
\hline 己4. & 己4. & $\neg コ 己$ \\
\hline 更慈 & 日品 & 一「テ元百更更 \\
\hline 您当 & 心等 & ，1 1 你你你你你您您您 \\
\hline 間 $\frac{4}{7}$ & 門员, & I「队阼門門門閒閣閒間 \\
\hline 牙 $\bar{r}$ & $\int_{\vec{r}}$ & 一千乎牙 \\
\hline 晨乞 & 日㕫 & ‘口ロ日旦児昵晨晨晨晨 \\
\hline 牀紊 & 乎这 & 24 月韭韭壯壯鼎 \\
\hline 到各 & 刀(リ) & 一こ㕕至至到到 \\
\hline 遲 & 定 (之) 礼 & 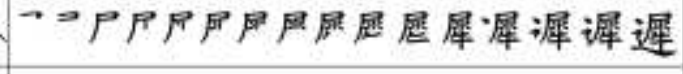 \\
\hline 齒 & 踩※゙ & 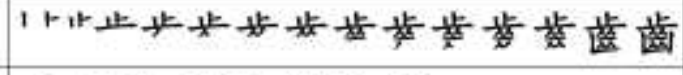 \\
\hline 刷店 & 刀 (リ) & ナコ尸居局尼尼刷 \\
\hline 亮茫 & 肉是 & 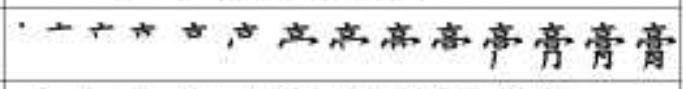 \\
\hline 得各 & 多未 & ’ 乡 行得得得得㫜得得 \\
\hline 拿光 & 手 $(f)_{x^{\prime}}^{r}$ & 人 人AA合令食食拿 \\
\hline 梳: & 木只 & 一十才材杜㭕梳梳梳 \\
\hline 借浆 & 人 $($ 保量 & １ 1 什什体供借借借 \\
\hline
\end{tabular}

Figure 8 no blanks for COLs to practice writing 

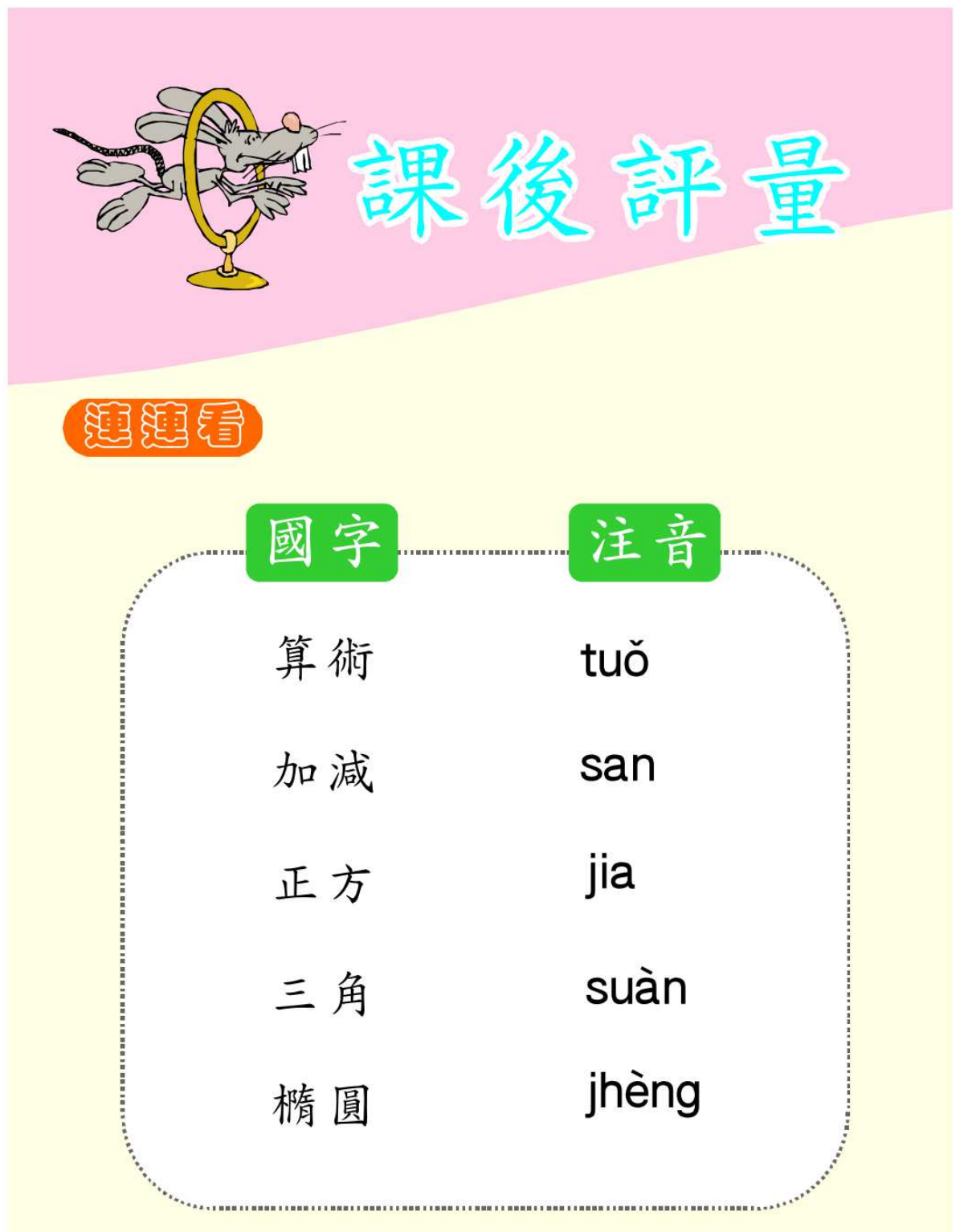

66

Figure 9 Errors marks for Chinese phonetic symbols

The evaluation reveals that the use of punctuation marks is sometimes a mixture of Chinese and Western styles. On top of that, there are typos such as misuse of " 、" as “, , . (Figure 10). 


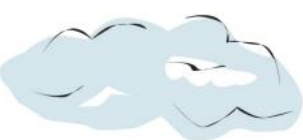

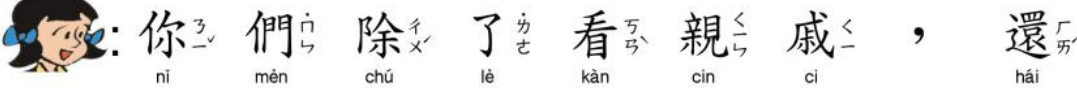

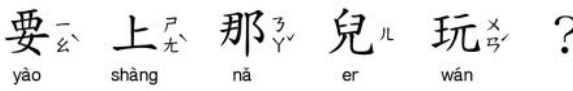

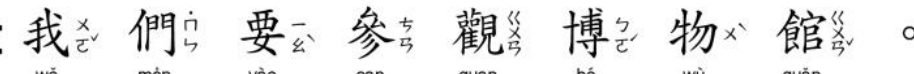

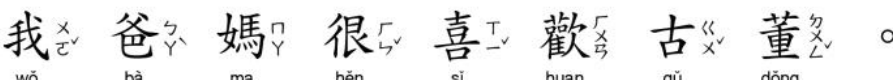

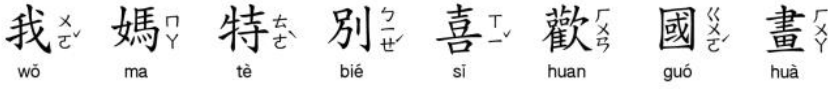

和分瓷吉器々

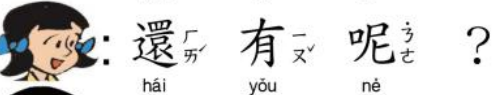

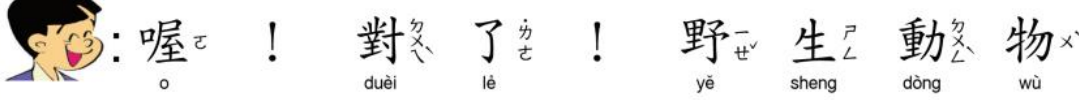

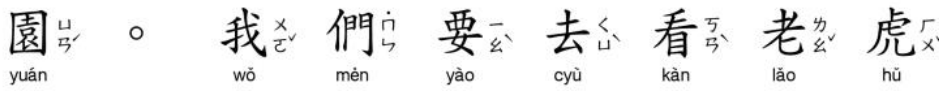

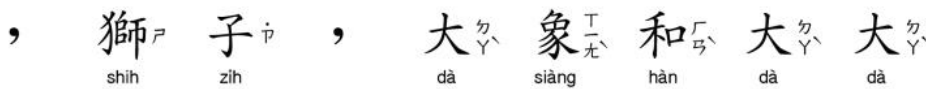

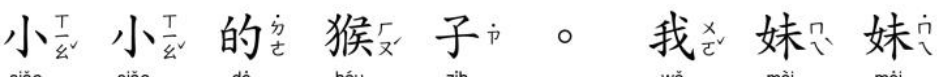

最忠喜I、歡希台劳灣号猴区。

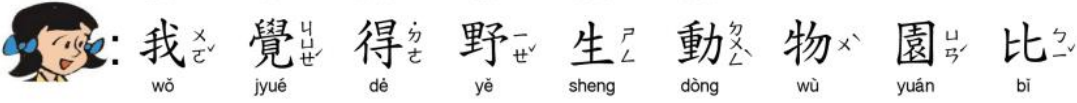

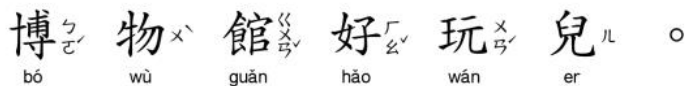

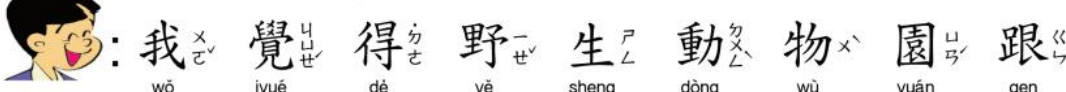

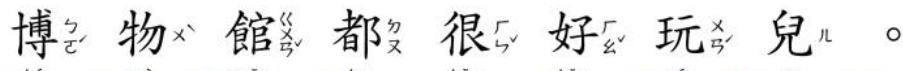

54
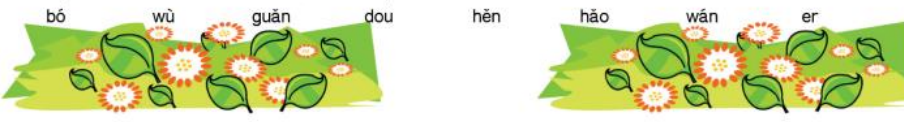

Figure 10 misuse of " 、" as “ , " 


\section{Engagingness}

Table 5 is the itemized result, with description on the left and point on the right.

Table 5 Scores in engagingness

Items $\quad$ Scores

Practical and interesting content 3

Providing learners with a pleasant 2

learning experience

Children-relevant topics

3

Diversified layout and illustrations

2

There is an abundant variety of topics in the Children's Chinese Reader, including greetings, numbers, body, food, animals, weather, personal and family life, appellation terms, school life, leisure activities, interests and hobbies, and so on. The content depicts naturally occurring events, so they are close to children's daily life. However, the content is a bit dull because of constant repetition of the item targeted for mastering. For example, in the dialogue 'Computer Games' in Lesson 2, Book 4, numbers and direction words such as left, right, up and down are presented so constantly that children feel bored

The audio-lingual method emphasizes the importance of practice with a lot of exercises and the Children's Chinese Reader does provide lots of exercises. However, there are more practice in reading and writing than in listening and speaking. Only one gamebased activity is provided in each lesson in teacher's manuals, and not all of them are interesting and competitive. For example, the storytelling for Lesson 2, Books 8 can be merely regarded as a speaking practice, not a game activity.

Topics in the Children's Chinese Reader are related to the actual life of children living in North America, such as fruit pie (Lesson 3, Book 2), Christmas (Lesson 2, Book 9), Going Barbecue (Lesson 2, Book 5), and so on. Topics that children are interested in 
are also provided, such as playing baseball (Lesson 1, Book 5), Barbie (Lesson 4, Book 5), swimming (Lesson 3, Book 5), etc. However, some topics are not children-relevant. For example, the topic 'driving' in Lesson 2, Book 7, including vocabulary, such as 'turning lights, 'rearview mirror', etc., is not practical for children who cannot drive.

Exquisite illustrations not only effectively assist teaching, but also enhance the attraction of teaching materials. In particular, pictures for children's textbooks are indispensable. These pictures alse provide students with a situation that helps them understand the content. Each lesson is presented with broadsheet illustrations and are consistent with the topics (Figure 11). However, the illustrations on pages other than that on the title page are all too small so that the text occupies most of the space, which increases the children's burden in learning, and the layout is not eye-catching and diversified. In addition, the illustration in each lesson is little line with the text. For example, the topic in Lesson 2, Book 3 is "Puppy", but the illustration is "bee" which has nothing to do with the text (Figure 12), so COLs are likely to be confused. 


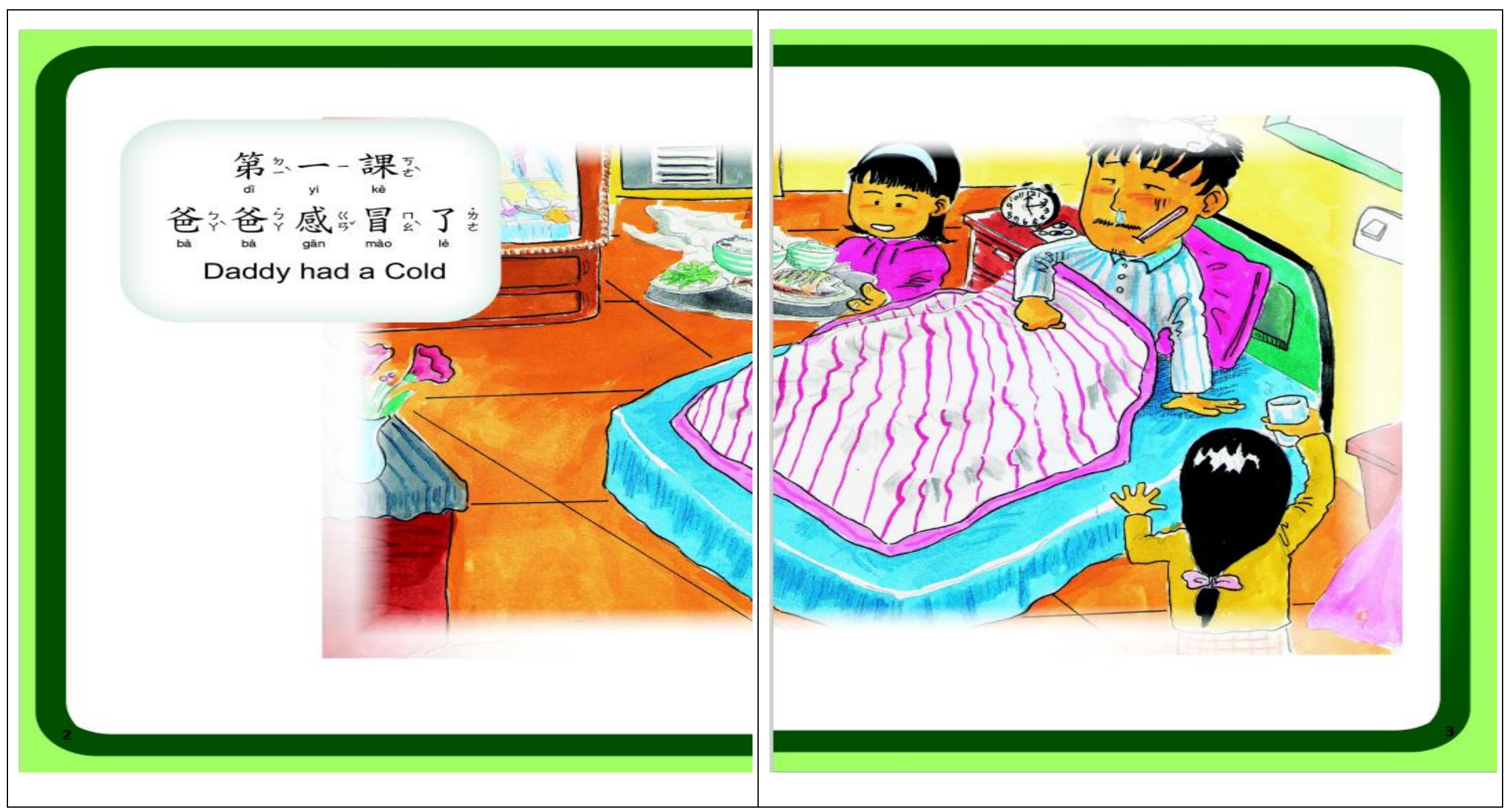

Figure 11 A broadsheet illustrations 


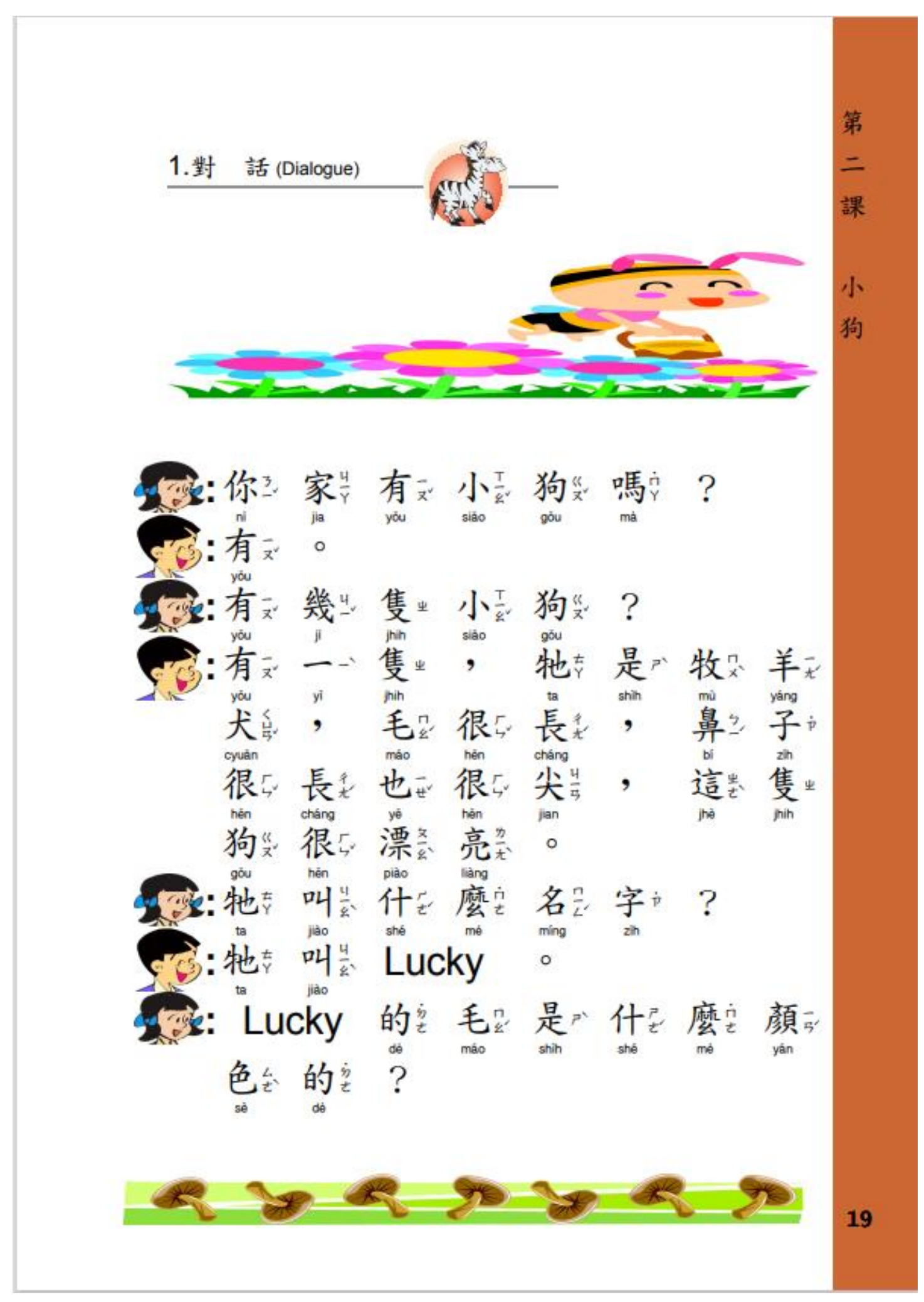

Figure 12 The illustration is little line with the text

Also, the sentence pattern exercises in the textbook do not clearly indicate the focuses. For example, one of the sentence pattern exercise in Lesson 4 of Book 1 (Picture 13) is $\ulcorner\ldots$ 要不要...點兒...」" Do you want to...", but the explanation is not clear enough 
for students to catch the key points. Moreover, from the Book 10 to Book 12, black lines underlining the grammatical key points are not effective obvious enough, so it to change the using a different color for the underlining and marking key points is recommended. On the whole, the layout is a bit monotonous and not interesting enough.

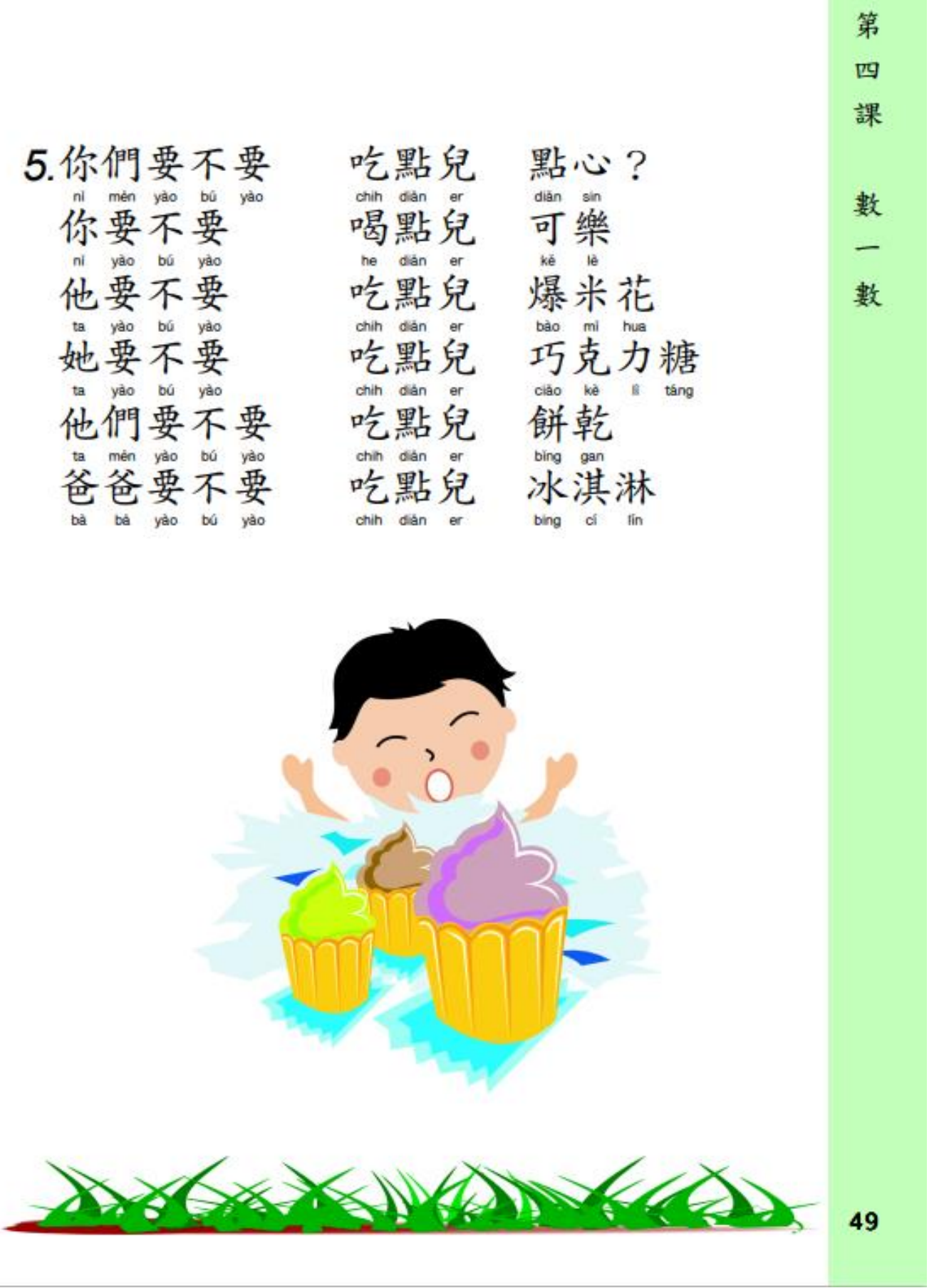

Figure 13 An unclear indication 
Systematic-ness

Table 6 is the itemized result, with description on the left and point on the right.

Table 6 Scores in systematic-ness

Items Scores

$\begin{array}{lll}\text { Systematic Language } & \text { elements } 2 \\ \text { (phonetics, vocabulary, } & \text { grammar, } \\ \text { Chinese characters) } & \end{array}$

Practicing four different language skills 2

at the same time

Providing teacher's manuals $\quad 4$

Providing workbooks 4

Providing test papers 1

Providing audio files 1

Providing video files 1

The Children's Chinese Reader has 12 books with a total of 1,160 Chinese characters, 1,536 vocabularies, and 217 sentence patterns. Most of the vocabulary is concrete, and related to daily activities. Abstract vocabulary, such as 安慰 comfort, 盡力 effort, 樸 實 simplicity, and 省事 trouble-saving, etc. is not shown until in Book 11 and 12. The content from Book 1 to Book 4 is related to daily life; the content from Book 5 to Book 10 focuses on social communication, and the content in Book 11 and 12 is about idiom stories. The texts in the Children's Chinese Reader are graded in the order of difficulty, which fits children's cognitive development.

The longer passage-based texts that start from B8 may appear difficult and frustrating to learners who are accustomed to the shorter dialogue-based texts in the first seven 
volumes.

Besides, listening- and speaking- based exercises in the workbook are much emphasized in the first seven volumes, with little emphasis on writing, particularly character writing. For the benefits of acquiring the proper way to write Chinese characters, there should be an increasing amount of writing practice throughout the first 7 volumes.

In addition to the content, the Children's Chinese Reader also provides users with teacher's manuals and workbooks; however, audio and video files cannot be found online. Creating e-learning resources in new edition is recommended.

\section{Conclusion}

In Chinese classes for children of other languages (COL), the content of textbook is critical to the quality of teaching. Using assessment indicators of COL textbooks developed by Wang (2008), this study concluded advantages and limitations for the Children's Chinese Reader as follows:

Background

In the category of background, the incorporation of teaching methods and Chinese linguistics and culture in the textbook is up to par. However, two criteria have much to be desired: the need of lesson plans, syllabi, and teacher manuals to complete a textbook (Zhang et al., 2019), and structural learnability that fits children's psychological process of learning (Acar, 2019; Education Bureau of Hong Kong, 2016; Kempe et al., 2019) even though there are signs of grammatical points presented in stages, and comic pictures illustrated by a famous Taiwanese cartoonist.

Specificity

There are the Hanyu pinyin and Chinese phonetic symbols (Zhùyīn fúhào) in the Children's Chinese Reader. Both phonetic systems are good to the COLs and transnational students in Taiwan. The topics, such as festivals and idiom stories, have been added in the 7th volume of the Children's Chinese Reader, providing COLs with daily vocabulary, ethic and cultural content; however, too much vocabulary and excessively long dialogues will result in the COLs' learning loadings and lower their interests in learning Chinese. Therefore, it is recommended to moderately reduce the 
content of the Children's Chinese Reader by referring to the content of Chinese textbooks for Taiwanese elementary school students in Taiwan

\section{Practicality}

This study found that the content of the Children's Chinese Reader is not practical for COLs to immediately apply what they've learned because unnatural dialogues not often spoken in real life are shown in the textbooks. Its exercises in the workbooks are not diversified except for blank filling questions, and have no grading standards. It is suggested to add multiple exercises and point allocation for a total of one hundred points, so that teachers and COLs' parents can help them do self-testing.

\section{Scientific-ness}

Integrating the foregoing analysis, the average score for scientific items is 2 points. Although the content of the Children's Chinese Reader conforms to the norms of language teaching, there are still shortcomings in the compilation. Firstly, the publishing time precedes both the guideline of COL's Chinese proficiency and the recommended vocabulary list with contexts for children's Chinese competency certification (CCCC), which were developed by the Taiwan Steering Committee for the Test of Proficiency-Huayu, so the content does not completely follow the guideline. It is recommended to re-check and adjust vocabulary that is in line with the COL's Chinese proficiency. Secondly, the cultural vocabulary should be illustrated with pictures than translation only. In addition, there are typos in punctuation, translation and sentences, causing semantic and grammatical ambiguity. Therefore, it is recommended to double check, modify, and republish.

\section{Engagingness}

For children, an interesting textbook triggers their learning motivation. This study found that the content is close to COLs' life, but it is a bit dull. The exercises are so repetitive that COLs easily feel bored. Although there are illustrations in the Children's Chinese Reader, the picture-text ratio is not balanced. One disadvantage is that there are more texts than illustrations; another is that some illustrations with are unrelated to the texts. These layout problems cause COLs' lower learning motivation. 
The Children's Chinese Reader is equipped with teacher manuals and workbooks; nevertheless, no worksheets and test papers offered mean that teachers need to spend much time creating test materials for their students. No one disagrees that listening, speaking and then reading and writing is the order of foreign language learning, and the four skills practicing are important for any L2 learners; however, the text format is conversational-based from the 1st to 7th volume of the Children's Chinese Reader, and only short texts are shown from the 8th to 12 th volume without dialogues. These texts are not short in length and a little difficult to read for COLs. It is recommended that the ratio among listening, speaking, reading, and reading should be balanced for revision.

Although the population of Chinese learners has gradually extended from adults to children, the majority of research focuses on adult Chinese L2 learners. Hence, this exploratory study can offer future study insights on the benefits of COL textbooks. Teaching Chinese to speakers of other languages is concerned with target learners. Age is a key independent variable to influence not only Chinese L2 learners' performance but the development of the textbooks besides nationality and Chinese language level. If only a single set of criteria is used to measure all Chinese textbooks or a single textbook is used for all COLs, its applicability can be debatable. Therefore, future studies can refer to this study to construct assessment indicators weight systems for Chinese textbooks for various Chinese L2 learners, and improve COL Chinese textbooks.

\section{References}

Behnke, Y. (2018). Textbook effects and efficacy. In E. Fuchs \& A. Bock (Eds.), The Palgrave Handbook of Textbook Studies (pp.383-396). Palgrave Macmillan.

Bouzid, H. A. (2017). An evaluation of selected Moroccan ELT textbooks: A standardsbased approach perspective. Indonesian Journal of Applied Linguistics, 7(1), 229-238. https://doi.org/10.17509/ijal.v7i1.6879

Cai, Q.-Y. (2021). Constructing assessment indicators weight system of digital business $\begin{array}{llll}\text { Chinese } & \text { materials. }\end{array}$ https://doi.org/10.1177/21582440211047555

Chen, H.-C. (2014). Cultural “internalization” for overseas Chinese teaching materials. http://xiaoan.web.fc2.com/dongyahanxue/paper/no3/papers/15.pdf Chiu, H.-C. (2017). An analysis study of Mandarin Chinese teaching materials of young 
children (Unpublished master's thesis). National Pingtung University.

Czerwionka, L. (2015). Collaborative textbook selection: A case study leading to practical and theoretical considerations. L2 journal, 7(2), 1-13.

Dewi, K. (2016). Analysis of kindergarten Mandarin teaching materials 'Chinese Paradise'. Jurnal Bahasa dan Budaya China, 7(2), 84-91.

Dong, L.-1. (2017). Compiling Chinese textbooks for specific countries in international Chinese education. https://h.pku.edu.cn/docs/201811/20181114205031886996.pdf

Education Bureau of Hong Kong (2016). Guiding principles for quality textbooks (Revised June 2016). https://www.edb.gov.hk/en/curriculumdevelopment/resource-support/textbook-info/GuidingPrinciples/index.html

Guan, L. (2020). Task-based Chinese textbook compiling principles: Take experience Chinese as an example. Modern Education Forum, 3(7), 105-107. DOI:10.12238/mef.v3i7.2578

Guo, X. (2012). The application of interesting principle in teaching Chinese to children as a foreign language (Unpublished master's thesis). Soochow University.

Guo, X. (2017). On the systematic principles of compiling Chinese teaching materials for foreigners. Modern Chinese (Teaching Research), 7, 152-154.

Huang, F. (2010). On the principles of compiling and selecting teaching materials for $\begin{array}{lllll}\text { Chinese as language. } & \text { a }\end{array}$ https://m.inrrp.com.cn/html/921b55573967bf5f.html

Huang, X., \& Huo, B. (2005). Looking for the theoretical basis for curriculum and textbooks. People's education press.

Li (2002). A Review on the compilation and research in teaching materials for Chinese as a foreign language in the past 20 years. Applied Linguistics, 3, 100-106. DOI: 10.16499/j.cnki.1003-5397.2002.03.016

Li, J. (2016). On the principles of compiling teaching materials for comprehensive Chinese as a foreign language. Journal of Language and Literature Studies, 10, $152-154$.

Li, Z. (2010). Scientific Issues in compiling materials of teaching Chinese as a foreign: Editors' experiences of International Children's Chinese. Publishing Journal, 18(4), 31-34. DOI:10.13363/j.publishingjournal.2010.04.017

Liu, X. (2002). Introduction to teaching Chinese as a second language. Beijing Language and Culture University Press. 
Ma, X. (2008). A Probe into the engagingness of cultural textbooks for Chinese as a foreign language. Language Journal, 22, 17-18.

Mahmood, K. (2011). Standardization of textbook evaluation criteria through development of quality textbook indicators. https://piqc.edu.pk/casestudies/Dr_Khalid_Mahmood_Standardization_of_Text book_Evaluation_Criteria_Through_Development_of_Quality_Textbook_Indic ators_Education_Quality_Case_Study_PIQC.pdf

Mustami, M.K., Syamsudduha, S., Safei and Ismail, M.I. (2019). Validity, practicality, and effectiveness development of biology textbooks integrated with augmented reality on high school students. International Journal of Technology Enhanced Learning, 11(2), 187-200.

Smart, A., \& Jagannathan, S. (2018). Textbook policies in Asia. Asian Development Bank.

Stern, L., \& Roseman, J. E. (2004). Can middle-school science textbooks help students learn important ideas? Findings from project 2061's curriculum evaluation study: Life science. Journal of Research in Science Teaching, 41(6), $538-568$.

Tsai, R.-C., \& Shu, Z.-M. (2017). Chinese Teaching Materials Compilation Practice for TCSL. Sharing.

Wang, K. (2015). On the practical principles of compiling Chinese teaching materials for foreigners. Intelligence, 22, 266-268.

Wang, L-L. (2008). Essentials for compiling Chinese textbooks for children. https://docsplayer.com/165874177-4d-f736f-fd20a8e0b5a3b5d8bb79b1d0a7f7bd73bc67ad6eb6b5.html

$\mathrm{Xu}$, Z. (2009). On the compilation of Chinese textbooks for overseas children. In Beijing Foreign Studies University (Ed.), International Chinese education (3rd ed., pp. 3-9). Foreign language teaching and research press.

Yeh, Y.-T. (2010). The impact of AP Chinese on the Chinese heritage schools in the US: Investigate in Southern California Palos Verdes School District (Unpublished master's thesis). National Taiwan Normal University.

Zhao, J. (2005). Introduction to teaching Chinese as a second language. The Commercial Press. 